\title{
Design and Analysis of Grid Tied Single Stage Three Phase P-V System Adarsh Gupta ${ }^{a}$, Dr. Omveer Sing $h^{b}$
}

School of Engineering, Gautam Buddha university, Greater Noida, India ${ }^{a}$

School of Engineering, Gautam Buddha university, Greater Noida, India ${ }^{b}$

gadarsh79@gmail.comª, soeee.ovs@gmail.com ${ }^{\mathrm{b}}$

\begin{abstract}
This paper makes a proposal for a $50 \mathrm{~kW}$ single-stage solar system which is PWM based DC-AC converter with three-phase grid connection with a combined power of $53 \mathrm{kw}$ at $1000 \mathrm{w} / \mathrm{m}^{2}$ irradiation by using 21 series and 11 parallel panel strings, a device built to process energy from a photovoltaic array made up of SunPower SPR-230E-WHT-D PV module for any solar radiation with a high-power factor. This paper introduces a control strategy for Photovoltaic generation systems with a three-phase grid connection and utility power factor in any circumstance of solar radiation using Park's transformation (dq0 transformation) which operators with current control mechanism to increase power efficiency. Loads attached to the device produce reactive power and harmonic components that can be compensated by the system.
\end{abstract}

Keywords: Photovoltaic cell, Maximum power point, Inverter, Renewable energy sources, Power system.

\section{Introduction}

Many concerns have arisen as a result of the use of fossil fuels as a primary source of power production. In terms of power generation, India ranks sixth. Thermal power plants produce approximately 65 percent of India's energy, while hydroelectric power plants generate 22 percent, nuclear power plants generate 3\%, and other alternative sources such as solar, wind, and biomass generate the remaining 10\%. India's large coal reserves have 53.7 percent of the country's commercial electricity demand. The use of green technology, such as a solar energy system, is often used to remove or mitigate such problems. The most serious problem associated with the use of fossil energy is global warming; where the rise in fossil fuels such as oil and natural gas are used to generate electricity through several decades result a number of environmental as well as health issue.

Solar cell-based photovoltaic power generation that is ready to direct conversion of solar energy to DC Electricity has the potential to be a clean energy source and it can be broadly pertinent renewable energy source accessible for forthcoming energy production. As a result of photovoltaic processing developments over the last few decades, the participation and role of electric utilities in PV has increased significantly. Observations on the inverter's DC side are needed thus to measure and sustain tracking, MPPT algorithms are used for the highest operating point at every instant. Numerous approaches have been found and discussed in this decade in order to reduce or to get rid of these measurements, the system's complexity is minimized, and it is more cost-effective.

The DC/DC converter controls full output, while the DC/AC converter synchronizes and feeds required power to the grid in a two-stage topology, is one of many approaches for a sensor-less MPPT algorithm. 1-3. However, such strategies necessitate at least one calculation, such as current or voltage 
on the DC side of the converter, as well as a large number of power switching instruments. Other methods, on the other hand, use a one stage converter topology, which has the benefit of reducing the number of conversion steps and power switching units. There has been a decrease in a number of sensing elements in one stage topology, and On the DC side of the converter, MPPT algorithms need at least one sensing component, which involves filtering the calculated values to have the DC quantities on average, necessitating more computing power from the controller, and it was suggested for the MPPT algorithm to work based on only measuring PV panel current 4-10..

There is various research works going on the power quality enhancement of PV systems such as elimination strategies or harmonic compensation. When the generated electrical power from the renewable energy resources is supplied to grid through the grid connected inverter, the inverter should be providing zero steady-state error, fast response, and robustness to disturbance. In addition to that the grid-connected inverter should effectively compensate the imbalance in the system, reactive power, and harmonic. Conventionally, the simple PI control is used to regulate the grid-connected inverter. The distortion caused by harmonics under the distorted grid cannot be adequately compensated using the PI controller.

Henceforward, this paper presents a grid connected PV system and the control strategy of the inverter and that is based on control of active and reactive power using Park transformation or dq0 transformation in three phase grid connected PV system. The MPPT based controller for DC-AC converter is designed in this paper using Perturb and Observe.

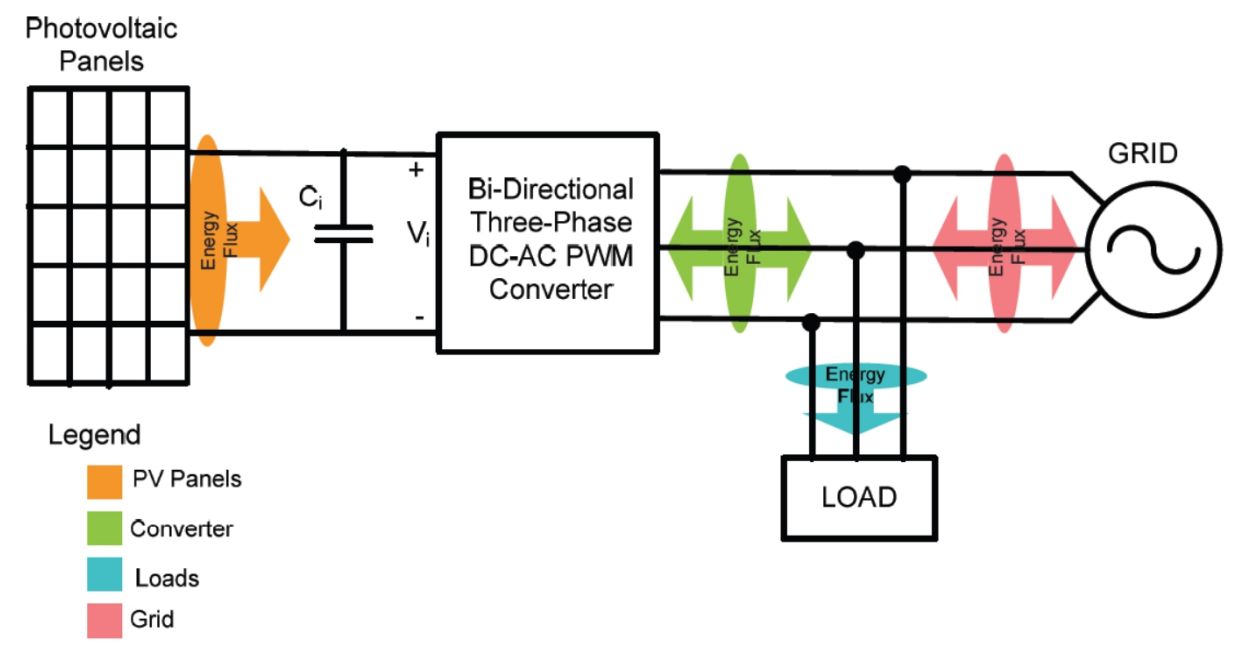

Figure 1: Proposed three-phase photovoltaic power system.

\section{Review from Old Research}

K.H. Hussein et al. 14. Introduced a new Maximum Power Point Tracking (MPPT) algorithm that compares the continuous and instantaneous conductivity of the material of the PV array to monitor the Maximum Power Operating Point (MPOP). The author of this paper discovered some flaws in the Perturb and Observe approach and demonstrated that the Incremental Conductance algorithm 
effectively monitored the MPOP. The work was carried out by both simulation and graphs.

Villalva et. al. 15. explained the current ecological and climate conditions, particularly sun-oriented irradiance, temperature, and wind speed, are reported and analyzed in his paper. At around the same time, the prompt information from the plant including PV module temperature, electricity, current, and voltage are provided timely. The power reduces as the surrounding temperature rises. Another Fuzzy Logic-based approximation is proposed to greatly reduce the power decline under halfway concealing conditions.

Sridhar R. 16. proposed the display and reconstruction of a photovoltaic model. The PV exhibit is displayed, and its voltage current characteristics, as well as the strength and voltage values, are recreated, taking into account the temperature and sun's irradiance. This allows the PV framework's components to be successfully recreated and advanced. The natural components have an effect on the yield qualities of a PV exhibit, and the transformation productivity is poor. As a result, a maximum power point monitoring (MPPT) protocol is required to monitor the maximum potential in order to increase the generated vitality.

E. Vartiainen et. al. 17. explained the radiant irradiance on a sloping or leaning in a particular direction surface is usually estimated from hourly flat irradiance estimations using a slant irradiance model It is also possible to calculate the slant irradiance by using a sky brilliance model to include the sky brilliance conveyance. Five slant irradiance models and six sky dissemination models are compared in this article, as well as hourly irradiance estimations on 24 slanted surfaces.

\section{Photovoltaic Array Modeling}

We can say that a solar cell is a kind of p-n junction diode that generates the charge carriers when the intensity of an incoming photon exceeds the semiconductor component's band gap. Many PV cells are attached in series and parallel to form a photovoltaic module and A photovoltaic array is a series or parallel interconnection of modules made up of several PV cells to attain the desired power. The model is ideally suited for the scientific conditions because it includes a series and parallel resistance as well as the observation of the terminal voltage.

The general equation for an individual solar cell is:

$$
\mathrm{I}=\mathrm{I}_{\mathrm{pv}}-\mathrm{I}_{0} e^{\left(\frac{\mathrm{qV}}{\mathrm{ah}}\right)}-1
$$

Here "I" represents current from an individual solar cell, The total current produced by solar irradiation is denoted by " $\mathrm{Ipv}_{\mathrm{pv}}$ ", the reverse saturation current or leakage current of the diode is denoted by using "I0", "a" denotes the ideality factor of the diode, which denotes the correction needed to conform the calculated values to the theoretical PN junction characteristics of a solar cell; the temperature of a diode in Kelvin " $T$ ", the charge of an electron can be represented by " $q$ " and " $k$ " is the Boltzmann constant. 
Eqn (1) does not adequately depict the features of a realistic solar cell. The model is ideally suited for the analytical situation with the inclusion of a series and in parallel resistance as well as the analysis of the terminal voltage.

$$
\mathrm{I}=\mathrm{I}_{\mathrm{pv}}-\mathrm{I}_{0} e^{\left(\frac{\left.V+I R_{(\mathrm{ser})}\right)}{a V_{(\mathrm{t})}}\right)}-1 .-\frac{V+I R_{(\mathrm{sev})}}{R_{(\mathrm{ger})}}
$$

Where, " $\mathrm{R}_{\text {ser" }}$ " specifies the total series resistance of all the solar cells connected, " $\mathrm{R}_{\text {per" }}$ specifies the total parallel resistance of solar cells connected, " $\mathrm{V}_{\mathrm{t}}$ " is the terminal voltage which can be calculated as " $\mathrm{V}_{\mathrm{t}}=\mathrm{kT} / \mathrm{q}$ " and "V" is the terminal voltage of combination of solar cells, and " $\mathrm{R}_{\mathrm{ser}}$ " exists due to the contact resistance between the connection terminal and the solar cell, whereas the p-n junction's leakage current gives rise to "Rper." The amount of parallel and series variations of solar cells used to create a PV array can be modified using Eqn (2). The voltage in a PV array can be increased by raising the series cell in the module, while the current level can be increased by increasing the parallel cells in the module. In this paper a PV array using Sun Power SPR-230E-WHT-D was used to validate the proposed methodology.

\section{System Modeling \& Control Method}

Typically, the first stage of this power system is applied to boost up or increase the value of voltage; however, having a two-stage power layer boosts the system's overall cost. Instead, single-stage power converters were proposed as a way to cut machine costs but, to increase the DC bus voltage, a series-connected panel group is necessary. Even though numerous solutions for increasing DC bus voltage have been suggested, in which applying a single-stage power layer operation with series-connected PV panels is the most popular method. 11-13. Inverters are divided into four groups depending on their output waveform: square wave, multilevel, sine wave and modified square wave. The converter modeling is straightforward, relaying on six IGBTs in the circuit. It is important to obtain current and voltage modeling for the desired output in order to implement the proposed technique. Figure 2 depicts a simplified electrical diagram of the converter. Pulse width modulation is a technique for adjusting the frequency of pulses in response to a small control signal in a pulse train.

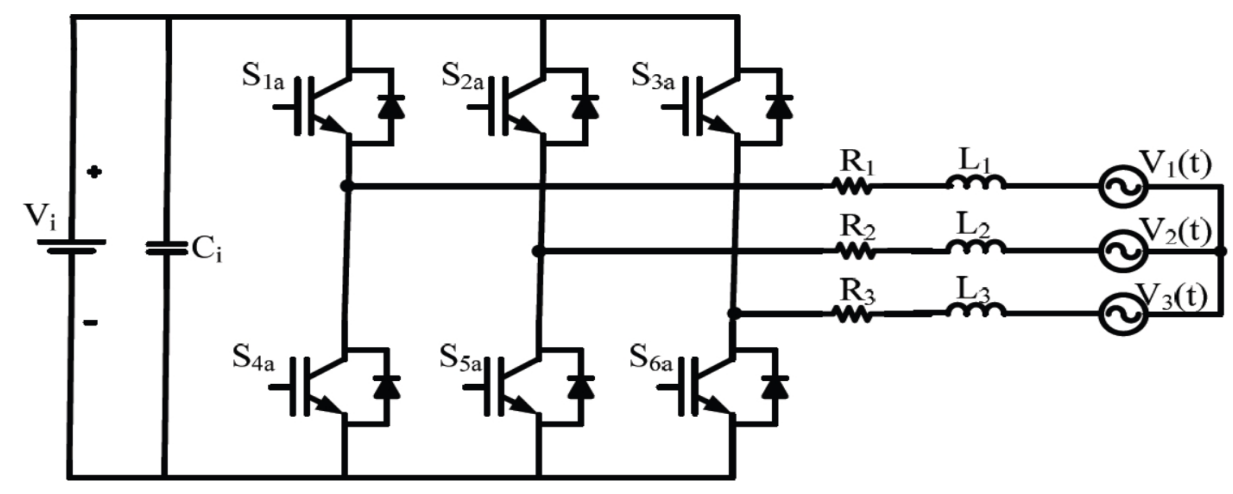

Figure 2: Bi-directional DC-AC PWM based inverter. 
Inverters with three phases are typically used in applications of high-power. Figure 1 demonstrates a general circuit system and control techniques. A three-phase power inverter connects the PV panel device along with the grid directly. Eqns. (3) and (4) can be used to measure the inductance and capacitance of the LC filter, respectively.

$$
\begin{aligned}
L_{f} & =\frac{0.1 U^{2}}{2 \pi f P_{p}} \\
C_{f} & =\frac{0.05 P_{p}}{2 \pi f U^{2}}
\end{aligned}
$$

The converter's bi-directional functionality is crucial in this proposed photovoltaic device because depending on the application, active and reactive power must be processed from the generator to the load and vice versa. Thus, the active and reactive power flows can be regulated with careful monitoring of the power switches. The inverter goes from one point out to another state to produce a waveform. Since current output has harmonics, an LC filter is used to minimize these harmonic distortions in the output current. For maximum power point tracking in a PV system, perturb and observation methods are used.

\subsection{Control Scheme}

The idea of current control simulation is to obtain the active input current clamping $\operatorname{Ii}(\mathrm{t})$. This active clamping makes following advantages to the system:

- Power flow management between the grid and the solar PV facility.

- And the Possibility to realizing MPPT of the PV panels.

By using P\&O method for the MPP tracking in the PV system and it is noticed that voltage values vary very little with time, the difference in solar irradiation intensity undergoes significant changes. In India, most of the places has no important and large temperature variation during the day.

The MPP approach is based on the most recent system of control and that is achieved by maintaining the voltage constant and close to the MPP in the PV terminals. An example is presented below for the current properties and voltage properties of a PV cell for various values of irradiation. 


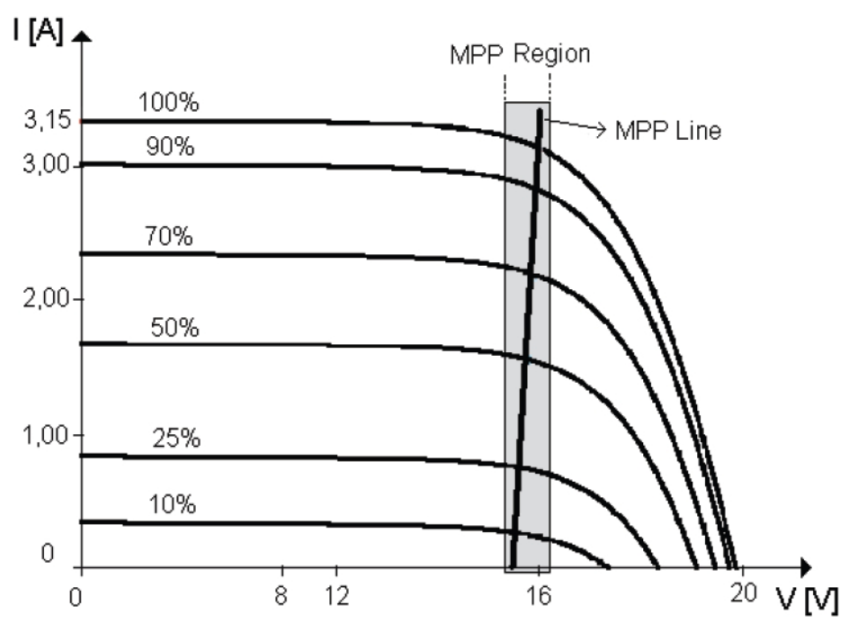

Figure 3: An Example of characteristics between Current and Voltage of a PV cell.

Keeping an eye on the MPP points and forming an MPP Line by linking them, it is seen and noticed that and as the rate of solar irradiation varies greatly, the voltage values remain relatively constant. In terms of temperature, there is no significant difference during daytime. When the voltage is kept "within" the MPP region, when the irradiation increases, the amplitude of the PV cell's current changes as well; however, the PV cell's output voltage is not affected significantly.

\section{Implementation of The control}

Figure 4 depicts the proposed grid-connected three-phase PV system's MATLAB model, control methodology, and modulation. As from Figure 4, output currents Ia, Ib and Ic from the inverter are obtained, and it is applied to Park's transformation by this $I_{d}$ and $I_{q}$ are obtained and used for active power and reactive power control in the system.

A reference current Iref is generated from the MPPT algorithm through the PV current and PV voltage. Because of the reference current value changes based on MPPT algorithm, the value of output current from the inverter varies in response to the irradiation curve. An error is generated through the Iref and $I_{d}$ for the active power control. The inverter currents efficiently follow the reference value Iref which is obtained by the algorithm. The Proportional Integral (PI controller) controller is the very popular controller used for providing feedback and error compensation. PI controllers are used to calculate an error value which is basically is the difference between measured current obtained from the inverter as an output and a desired injected current, the controller then makes an effort to reduce the error coming between them. Kp represents the proportional coefficient and Ki represents the integral coefficient, these are two autonomous constant parameters in the PI controller. The signal generated from error is multiplied by a Kp coefficient to form the proportional term of the controller. In time, this helps to reduce the overall error. The proportional coefficient, on the other hand, will not be able to reduce the error to low as zero, and there are always some steady state error present in the system. To minimize small steady state errors the Integral coefficient of the controller is used. This eliminates the steady 
state error and speed up the effort of the process into the reference point and Id_ref is obtained. With the same process Iq ref is obtained but with zero reactive power as input value. Changing the direct axis and quadrature axis currents will regulate the output energy and power factor.

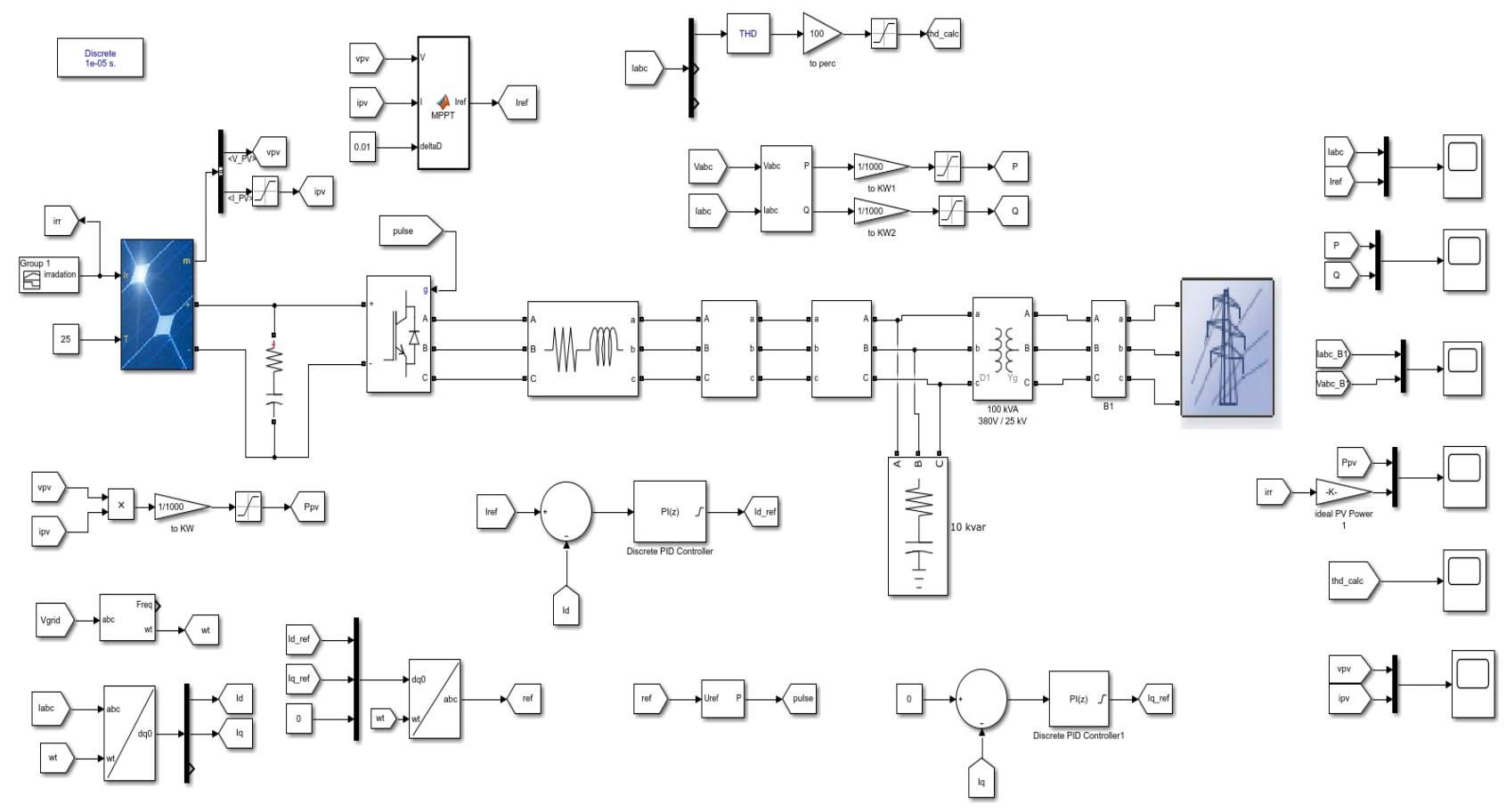

Figure 4: MATLAB Model for the Proposed System

The benefits of PI current control include a good steady-state reaction with a constant switching frequency, low current ripple, and well-defined harmonic content. We can apply PI controllers in the stationary $(\alpha \beta)$ reference frame as well as in synchronous reference frame (dq0 frame). Whenever a synchronous PI controller is applied, the control variables become DC and the PI compensators are able to minimize the fundamental component's stationary error to zero, while when PI controllers are used in a stationary configuration, the stationary error of the fundamental component is not reduced to zero, there is an intrinsic phase and amplitude monitoring error. In three-phase grid-connected inverters, current control in a synchronous reference frame using PI controllers is the standard solution.

To compensate for the current vector elements, the inverter applied with two Partial Integral controllers, which are specified in synchronous reference frame, as seen in the above figure 4. Outputs of both the PI controllers has been converter from synchronous reference frame to abc form and named as ref in the MATLAB model, further this generated signal has been passed through the block model called Phase Lock Loop (PLL) closed-loop control system, and an internal frequency oscillator tracks the frequency and phase of a sinusoidal signal. The internal oscillator frequency is adjusted by the control mechanism to hold the phase difference to zero. The obtained waveform works as the switching pulses for the six IGBTs based three phase inverter. 


\section{Simulation Results}

The system model has been designed and run as per suggested control configurations in Fig. 1 and the results can be verified and supported with simulation findings. Table I lists the simulation parameters. Simulation experiments have been conducted to verify the results. The simulation considerations are described in below Table I.

TABLE 1: System Parameters

\begin{tabular}{|c|c|}
\hline Grid Voltage (U) & $380 \mathrm{~V}$ \\
\hline Grid Frequency (f) & $50 \mathrm{~Hz}$ \\
\hline Nominal Power $(\mathrm{P})$ & $53 \mathrm{KW}$ \\
\hline Filter Inductance per Phase $\left(\mathrm{L}_{\mathrm{f}}\right)$ & $6.1 \mathrm{MH}$ \\
\hline Resistance of Inductor $\left(\mathrm{R}_{\mathrm{Lf}}\right)$ & $0.15 \Omega$ \\
\hline DC Link Capacitor & $100 \mu \mathrm{F}$ \\
\hline Switching Frequency $\mathrm{f}_{\mathrm{sw}}$ & $5 \mathrm{KHz}$ \\
\hline
\end{tabular}

First of all, dynamic performance of the PV system consisting with a modified version of current control algorithm has been tested at various irradiation with time along with this analysis few more analysis has been done on the basis of Simulation results such as under a variety of irradiation conditions control performance of power flow in the proposed control algorithm has been tested and analyzed. Figure 5 represents the irradiation curve under varying condition. Figure 6(a) represents the output voltage coming from the PV side and figure 6(b) represents current results of the PV panel respectively. The current obtained from the PV side is rising up to 62.48 Amperes, while the PV voltage remains relatively stable. It is triggered by the nature or design of MPPT control in PV system and provides data on control output.

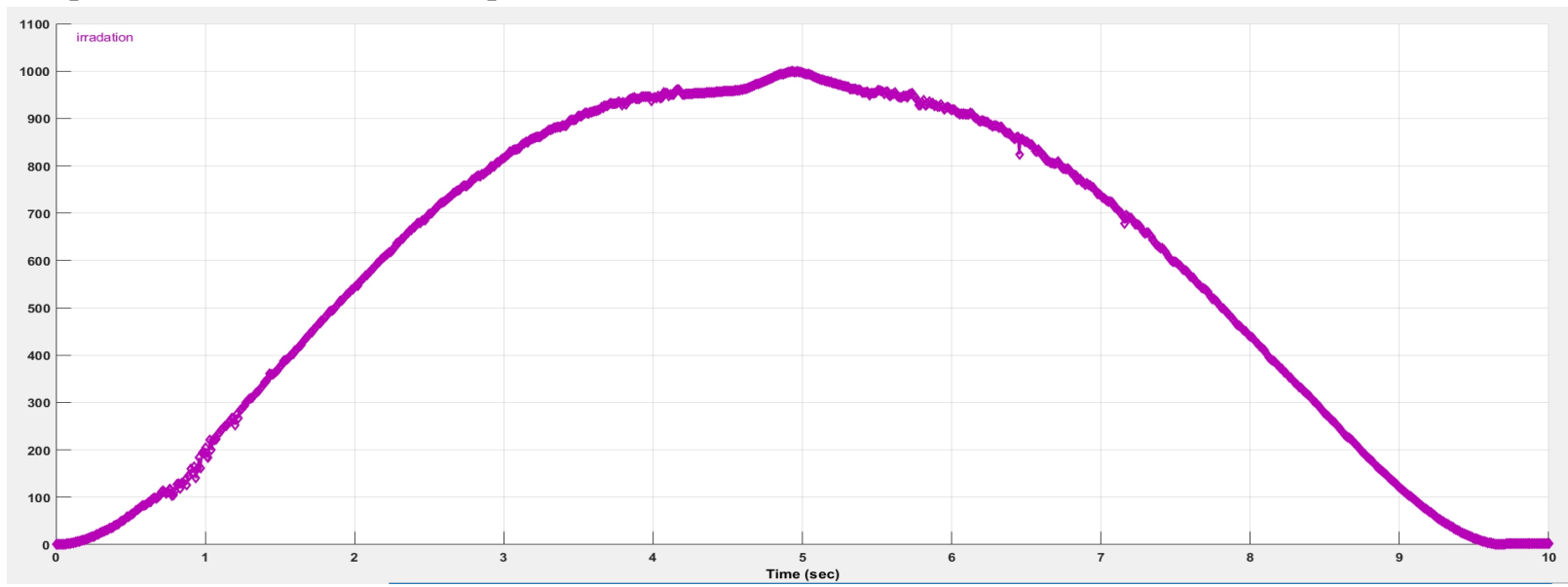

Figure 5: The irradiation curve 


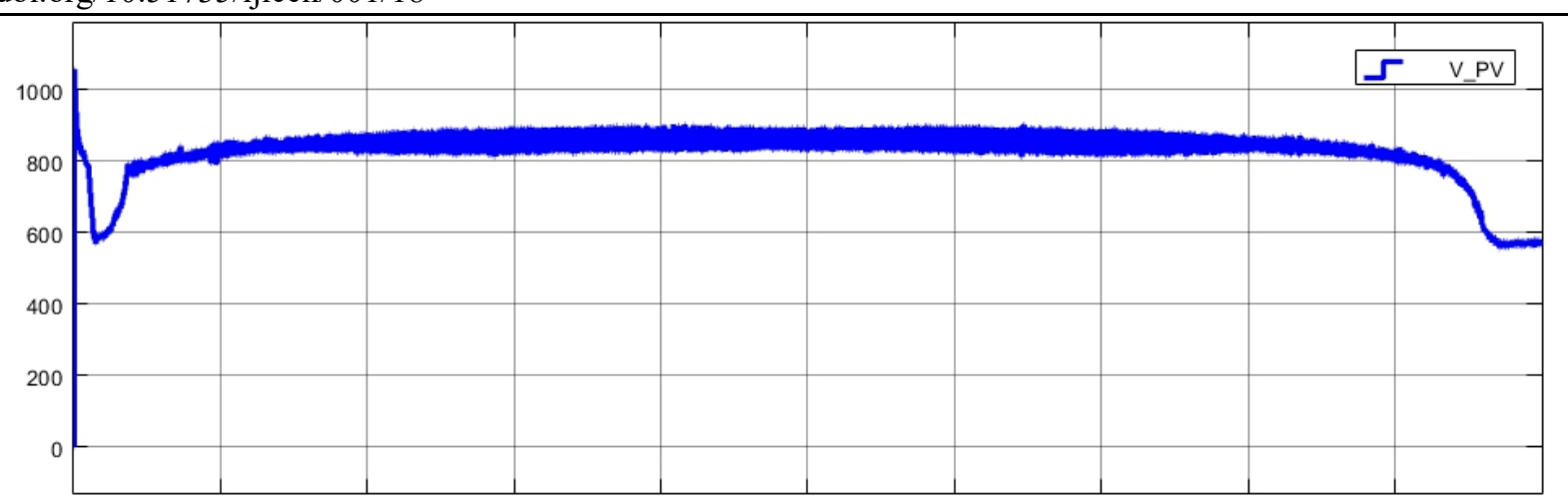

(a)

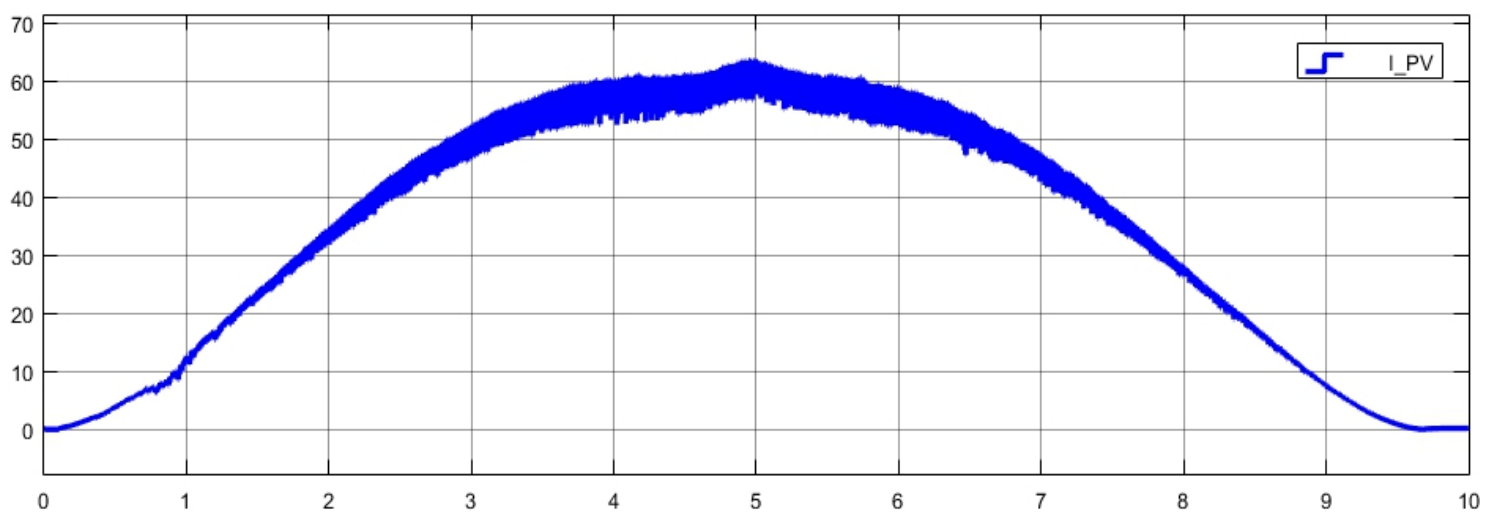

(b)

Figure 6: PV panel results (a) Voltage and (b) Current result

Above And Beyond the implementation test of the MPP Tracking algorithm, the inverter side is analyzed on the basis of power, efficiency, and harmonic distortions. The inverter currents are effectively and successfully following the reference value by the algorithm which is represented by Iref. The output currents of the inverter are also modified based on the irradiation curve since the MPPT algorithm adjusts the reference current value.

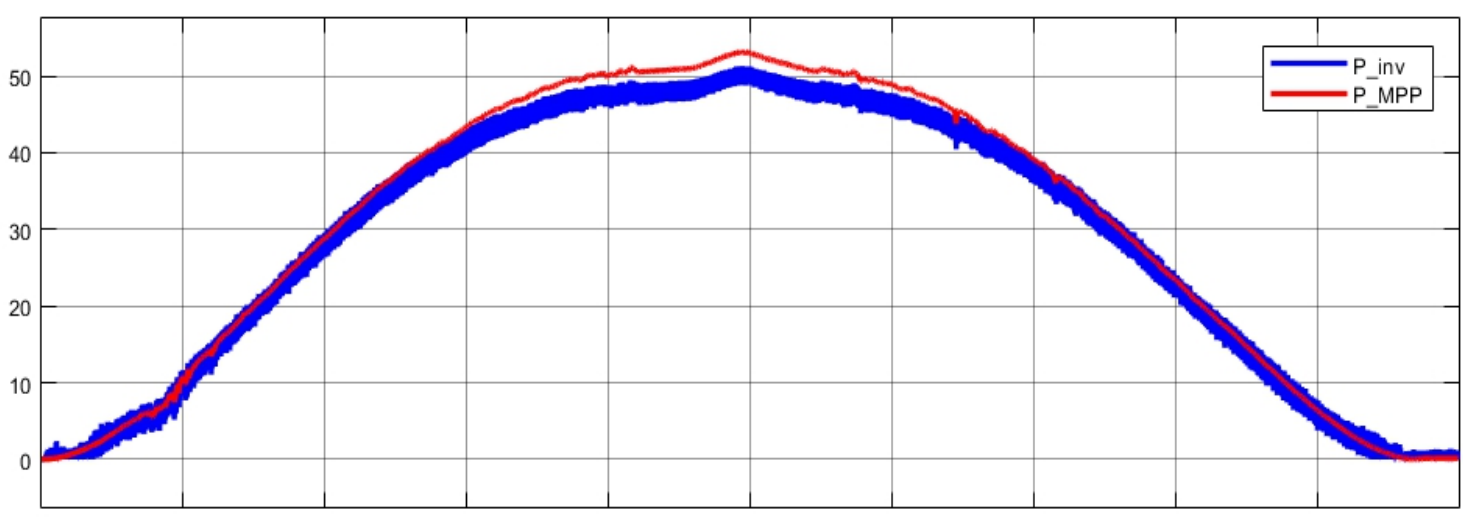

Figure 7: Comparison of the inverter and ideal MPP curves

To evaluate the overall performance of the proposed design, the transferred power to grid at the output of the inverter was compared to ideal MPP curves. Losses between the inverter output power and optimal maximum power curve has been shown in above Figure 7. Around the nominal capacity, 
power losses are especially high. It caused by filter inductance.

\section{Conclusion}

This article proposes a control algorithm which is basically combined form for current controlling in PV systems. MPPT algorithms and a controlling approach essentially based on the dq0 transformation was proposed for active power controlling as well as reactive power controlling of a three-phase PWM inverter to be used in a grid-connected photovoltaic generation system. The key goal of this project is to develop a dual-function system that generates solar energy while still acting as an active power filter for the system. Under changing irradiation conditions, the algorithm provided accurate monitoring.

\section{References}

1. J. Krismadinata, N.A. Selvaraj, Rahim, "Hysteresis current control and sensor less MPPT for grid-connected photovoltaic systems", Published in IEEE International Symposium on Industrial Electronics, Vigo, Spain, 4-7 June 2007; pp. 572-577.

2. T. Matsui and Kitano, "Power sensor-less MPPT control scheme utilizing power balance at DC link-system design to ensure stability and response", Published in IEEE Industrial Electronics Society 27th Annual Conference, Denver, CO, USA, 29 November-2 December 2001; pp. 1309-1314.

3. S.S. Park, A.K. Jinda, A.M. Gole, "An optimized sensor less MPPT Method for PV generation system”, Published in Conference on Electrical and Computer Engineering, St. John's, NL, USA, 3-6 May 2009; pp. $720-724$.

4. S. Jain and V. Agarwal, "Comparison of the performance of maximum power point tracking schemes applied to single-stage grid-connected photovoltaic systems", Published in IET Electrical Power Application. 2007, 1, 753-762.

5. S. Duan, Y. Zhou, F. Liu, J. Yin, “An improved MPPT arithmetic and grid-connected control strategy for single-stage three-phase PV converter with LCL filter", Published in 3rd IEEE Conference on Industrial Electronics and Applications, Singapore, Singapore, 3-5 June 2008; pp. 808-813.

6. G. Loh, D. Li, Yi Tang, F. Gao, P. Wang, "Transient maximum power point tracking for single-stage grid-tied inverter”, Published in IEEE Energy Convers. Congr. Expo. 2009, 313-318.

7. Liu Jainzheng, Zhao Zhengming, Wu Libo, "A single-stage three-phase grid-connected photovoltaic system with modified MPPT method and reactive power compensation" Published in IEEE Trans. Energy Convers. 2007, 22, 881-886.

8. T.P. Lee, W.L. Yu, G.H. Wu, "A DSP-based single-stage maximum power point tracking PV inverter", Published in IEEE Applied Power Electronics Conference and Exposition (APEC), Palm Springs, CA, USA, 21-25 February 2010; pp. 948-952. 
9. H.A.C. Braga, V.S. Lacerda, P.G. Barbosa, “A single-phase single-stage, high power factor grid-connected PV system, with maximum power point tracking", Published in IEEE International Conference on Industrial Technology (ICIT), Vina del Mar, Spain, 14-17 March 2010; pp. 871-877.

10. V. Agarwal, and H. Patel, "MPPT scheme for a PV-fed single-phase single-stage grid-connected inverter operating in CCM with only one current sensor”, Published in IEEE Trans. Energy Convers. 2009, 24, $256-263$.

11. E. Kabalci, G. Bal and I. Colak, "Parallel DC-AC conversion system based on separate solar farms with MPPT control," Published in 8th International Conference on Power Electronics - ECCE Asia, Jeju, 2011, pp. $1469-1475$.

12. Necmi Altin, Ibrahim Sefa, and Saban Ozdemir, "Single stage three level grid interactive MPPT inverter for PV systems," Published in Energy Conversion and Management, Volume 80, 2014, pp. 561-572.

13. B. Farhangi, H. Iman-Eini, and S. Bacha, "A Reliable threephase transformerless grid-connected PV inverter with inductive DC link," Published in IEEE Journal of Photovoltaics, vol. 8, no. 5, pp. 1305-1312, Sept.2018.

14. K.H. Hussein, I. Muta, T. Hoshino and M. Osakada, "Maximum photovoltaic power tracking:an algorithm for rapidly changing atmospheric conditions," IEEE. Transmission and Distribution.

15. Villalva, Marcelo Gradella, and Jonas Rafael Gazoli. "Comprehensive approach to modeling and simulation of photovoltaic arrays." Power Electronics, IEEE Transactions on 24.5, 2019 pp. 1198-1208.

16. Sridhar, R., et al. "Modeling of PV array and performance enhancement by MPPT algorithm." Int J Comput Appl 7.5: 2018, pp. 35-39.

17. E. Vartiainen, "A new approach to estimating the diffuse irradiance on inclined surfaces,"Renewable Energy, Vol. 20, 2014. 